\title{
DEVELOPMENT OF THE METAL RHEOLOGY MODEL OF HIGH-TEMPERATURE DEFORMATION FOR MODELING BY FINITE ELEMENT METHOD
}

\author{
Oleg Markov \\ Department of Computational Design and Modeling Processes and Machines \\ Donbass State Engineering Academy \\ 72 Akademicheskaya str., Kramatorck, Ukraine, 84313 \\ oleg.markov.omd@gmail.com \\ Oleksiy Gerasimenko \\ Department of Computational Design and Modeling Processes and Machines \\ Donbass State Engineering Academy \\ 72 Akademicheskaya str., Kramatorck, Ukraine, 84313 \\ profalliance@i.ua \\ Leila Aliieva \\ Metal working by pressure \\ Donbass State Engineering Academy \\ 72 Akademicheskaya str., Kramatorck, Ukraine, 84313 \\ leyliali2017@gmail.com \\ Alexander Shapoval \\ Department of Manufacturing Engineering \\ Kremenchuk Mykhailo Ostohradskyi National University \\ 20 Pershotravneva str., Kremenchug, Ukraine, 39600 \\ shapovala@kdu.edu.ua
}

\begin{abstract}
It is shown that when modeling the processes of forging and stamping, it is necessary to take into account not only the hardening of the material, but also softening, which occurs during hot processing. Otherwise, the power parameters of the deformation processes are precisely determined, which leads to the choice of more powerful equipment. Softening accounting (processes of stress relaxation) will allow to accurately determine the stress and strain state (SSS) of the workpiece, as well as the power parameters of the processes of deformation. This will expand the technological capabilities of these processes. Existing commercial software systems for modeling hot plastic deformations based on the finite element method (FEM) do not allow this. This is due to the absence in these software products of the communication model of the component deformation rates and stresses, which would take into account stress relaxation. As a result, on the basis of the Maxwell visco-elastic model, a relationship is established between deformation rates and stresses. The developed model allows to take into account the metal softening during a pause after hot deformation. The resulting mathematical model is tested by experiment on different steels at different temperatures of deformation. The process of steels softening is determined using plastometers. It is established experimentally that the model developed by $89 . . .93 \%$ describes the rheology of the metal during hot deformation. The relationship between the components of the deformation rates and stresses is established, which allows to obtain a direct numerical solution of plastic deformation problems without FED iterative procedures, taking into account the real properties of the metal during deformation. As a result, the number of iterations and calculations has significantly decreased.

Keywords: hot deformation, hardening, softening, stress relaxation, FEM, hardening curve, pause, energy-power parameters, forging and stamping.
\end{abstract}

\section{Introduction}

In the FEM study of the hot stamping and forging operations, difficulties arise due to the nonlinearity of the properties of the material during high-temperature deformation $[1,2]$. The main 
idea of the existing methods for taking into account the nonlinearity of these properties is solving the problem in an elastic formulation and use additional iterations (successive approximations) to switch to the plastic properties of a deformable metal [3]. As a result, the total computation time increases, which makes the FEM method less efficient compared to other numerical methods [4]. A more complete account of the mechanical characteristics of the deformable metal is one of the most important reserves of intensification and increasing the efficiency of modeling forging and stamping operations [5].

In the process of hot deformation, the metal is strengthened, at the same time dynamic processes of return, polonium saturation and recrystallization occur, leading to relaxation of stresses (softening) in the material at forging and stamping temperatures [6]. Accounting for the phenomenon of thermal softening of metals and alloys allows to improve the technical and economic indicators of the production of metal products produced by hot deformation [7]. Practice shows that during hot deformation with pauses, it is possible to carry out operations with lower energy consumption for deformation [8]. Therefore, the establishment of a valid metal rheology, which is strengthened and rooted out during hot deformation to establish a stress-strain state is an important task in mechanical engineering [9]. The aim of the work is to develop a mathematical model that would repeat the rheology of the material during the implementation of forging and stamping operations, which will improve the accuracy of FEM and power parameters determination when forging large-sized forgings.

To achieve the aim, the following objectives are set:

- establish an analytical model of stress relaxation in the alloy during hot deformation;

- check the installed model with the actual behavior of the metal during the implementation of hot deformation.

\section{Establishment of an analytical model of stress relaxation}

When solving FEM problems, it is advisable to establish and set a real relationship between deformation rates $\{\dot{\varepsilon}\}$ and stresses when varying temperature and rate regimes during hot deformation, when viscosity appears in the alloy [10]. This ratio is necessary for setting the plasticity matrix $[\mathrm{K}]$ for the FE modeling and determination of stress components [11]

$$
\{\sigma\}=[D] \cdot\{\dot{\varepsilon}\}
$$

The main difference between irreversible (viscous) deformations and plastic solids is that the latter depend on the deformation rate, especially at elevated temperatures [12]. The alloy has a viscosity when the deformation rate affects the stress $\sigma=\sigma(\varepsilon)$. The viscosity of the metal is manifested in the fact that after deformation the internal stresses change with time. For the operations of forging and stamping, when the material is rotated with hardening, the Maxwell relaxing model is an exact model that takes into account the rheology.

The deformation degree, according to this model, consists of elastic $\overline{\varepsilon^{\mathrm{e}}}$ and viscous $\overline{\varepsilon^{v}}$ components.

$$
\bar{\varepsilon}=\overline{\varepsilon^{\mathrm{e}}}+\overline{\varepsilon^{v}}
$$

Differentiating expression (2), let's obtain:

$$
\begin{gathered}
\frac{\mathrm{d} \bar{\varepsilon}}{\mathrm{dt}}=\dot{\varepsilon}_{\mathrm{xx}}=\dot{\varepsilon}_{\mathrm{xx}}^{\mathrm{e}}+\dot{\varepsilon}_{\mathrm{xx}}^{\mathrm{v}} ; \\
\dot{\varepsilon}_{\mathrm{xx}}^{\mathrm{e}}=\frac{\mathrm{d}_{\bar{\varepsilon}}^{\mathrm{e}}}{\mathrm{dt}}=\frac{\mathrm{d}\left(\sigma_{\mathrm{xx}} / \mathrm{E}\right)}{\mathrm{dt}}=\frac{\left(\mathrm{d} \sigma_{\mathrm{xx}} / \mathrm{dt}\right)}{\mathrm{E}} ; \\
\dot{\varepsilon}_{\mathrm{xx}}^{v}=\frac{\mathrm{d} \overline{\varepsilon^{v}}}{\mathrm{dt}}=\frac{\sigma_{\mathrm{xx}}}{v} .
\end{gathered}
$$


So

$$
\frac{\mathrm{d} \bar{\varepsilon}}{\mathrm{dt}}=\frac{1}{\mathrm{E}} \frac{\mathrm{d} \sigma_{\mathrm{xx}}}{\mathrm{dt}}+\frac{\sigma_{\mathrm{xx}}}{\mathrm{v}},
$$

where $v$-dynamic viscosity, MPa $\times \mathrm{s} ; \mathrm{E}-$ Young modulus, MPa.
Accounting for the stresses $\sigma(0)$ at the time $t=0$ and fixed deformation $\left(\frac{\mathrm{d} \bar{\varepsilon}}{\mathrm{dt}}=0\right)$ of equation (6) takes the form

$$
\frac{1}{\mathrm{E}} \frac{\mathrm{d} \sigma_{\mathrm{xx}}}{\mathrm{dt}}+\frac{\sigma_{\mathrm{xx}}}{v}=0
$$

from where

$$
\sigma=\sigma(0) \exp [-\mathrm{t} / \mathrm{T}]
$$

where $\mathrm{T}$ - the pause time, $\mathrm{s}$.

$$
\mathrm{T}=\mathrm{v} / \mathrm{E}
$$

represents the time for which the initial stress decreases by a factor of $e=2,718$.

Thus, it can be assumed that Maxwell's environment takes into account the real behavior of the metal during high-temperature plastic deformation (hardening, as well as softening). The minimization provides a reduction in the resistance to deformation (in this case, by an exponential dependence) with constant deformation [13]

After introducing the notation T (7), let's rewrite Eq. (6)

$$
\frac{\mathrm{d} \sigma_{\mathrm{xx}}}{\mathrm{dt}}+\frac{\sigma_{\mathrm{xx}}}{\mathrm{T}}=\mathrm{E} \cdot \frac{\mathrm{d} \bar{\varepsilon}}{\mathrm{dt}} .
$$
has the form

Regarding $\sigma_{x x}$, expression (8) under the initial condition, when the time $t=0$ and $\sigma_{x x}=\sigma_{x x}^{0}$

$$
\sigma_{\mathrm{xx}}=\mathrm{e}^{(-\mathrm{t} / \mathrm{T})} \cdot\left\{\mathrm{E} \cdot \int_{0}^{\mathrm{t}} \frac{\mathrm{d} \bar{\varepsilon}}{\mathrm{dt}} \cdot \mathrm{e}^{(\mathrm{t} / \mathrm{T})} \cdot \mathrm{dt}+\sigma_{\mathrm{xx}}^{0}\right\}
$$

If $\sigma_{\mathrm{xx}}^{0}=0$ and the body also deforms at a constant rate, then the stresses change in time according to the law

$$
\sigma_{\mathrm{xx}}=\mathrm{E} \cdot \bar{\varepsilon} \cdot\left(1-\mathrm{e}^{(-\mathrm{t} / \mathrm{T})}\right)
$$

In real deformation processes, the rate is not constant [14]; therefore, to solve equation (8), let's define a function of the deformation degree. This function must be growing, as in the process of deformation the deformation degree increases. As such a function, it is possible to choose a monotonically increasing exponential function, which corresponds to the actual deformation processes (Fig. 1)

$$
\bar{\varepsilon}=\frac{T}{A} \cdot \dot{\varepsilon}_{x x}\left(1-e^{-\frac{A t}{T}}\right)
$$

Deformation rate in this case

$$
\dot{\varepsilon}=\frac{d \bar{\varepsilon}}{d t}=\frac{T}{A} \cdot \dot{\varepsilon}_{x x}\left(-e^{-\frac{A t}{T}}\right) \cdot\left(-\frac{A}{T}\right)=\dot{\varepsilon}_{x x} \cdot e^{-\frac{A t}{T}} .
$$




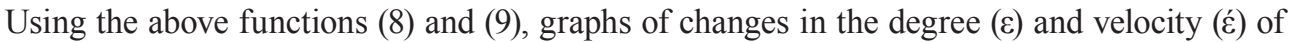
deformation in time are plotted (Fig. 1). The initial data for the calculations are: the pause time (T) is $2.0 \mathrm{~s}$; deformation rate $(\dot{\varepsilon})$ is $0.002 \mathrm{~s}^{-1}$; the deformation time (t) varies from 0 to 6 seconds. These output parameters correspond to the actual deformation processes (stamping or one press during forging).

These exponential dependencies correspond to the forging and stamping operations. In particular, with an increase in the degree of deformation, a hardening of the material and an increase in the size of the deformation zone occur, which leads to an increase in the deformation force [15]. As a result, the deformation rate exponentially decreases [16].

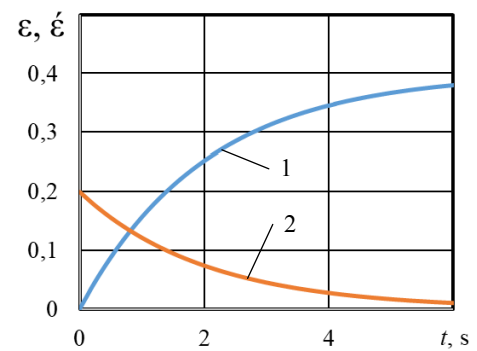

Fig. 1. Dependences of degree $\varepsilon$ and deformation rate $\dot{\varepsilon}$ on time: 1 - deformation degree; 2 - deformation rate

Substituting the deformation rate $\frac{\mathrm{d} \bar{\varepsilon}}{\mathrm{dt}}(10)$ into the desired equation (8), let's obtain the following differential equation

$$
\frac{\mathrm{d} \sigma_{\mathrm{xx}}}{\mathrm{dt}}+\frac{\sigma_{\mathrm{xx}}}{\mathrm{T}}=\mathrm{E} \cdot \dot{\varepsilon}_{\mathrm{xx}} \cdot \mathrm{e}^{-\frac{\mathrm{At}}{\mathrm{T}}}
$$

The resulting equation is solved by the variation method of a constant; for this, the homogeneous differential equation is first considered

$$
\frac{\mathrm{d} \sigma_{\mathrm{x}}}{\mathrm{dt}}+\frac{\sigma_{\mathrm{x}}}{\mathrm{T}}=0 ; \frac{\mathrm{d} \sigma_{\mathrm{x}}}{\sigma_{\mathrm{X}}}=-\int \frac{\mathrm{dt}}{\mathrm{T}} ; \ln \frac{\sigma_{\mathrm{x}}}{\mathrm{C}}=-\int \frac{\mathrm{dt}}{\mathrm{T}},
$$

so

$$
\sigma_{\mathrm{X}}(\mathrm{t})=\mathrm{C} \mathrm{e}^{-\int \frac{\mathrm{dt}}{\mathrm{T}}}
$$

To solve the inhomogeneous equation (8), let's apply the method of variation by a constant, replacing $\mathrm{C}$ with an unknown function $\varphi(\mathrm{t})$, then

$$
\sigma_{\mathrm{X}}(\mathrm{t})=\phi(\mathrm{t}) \mathrm{e}^{-\int \frac{\mathrm{dt}}{\mathrm{T}}}
$$

Differentiate (12) and obtain

$$
\frac{d \sigma_{x}}{d t}=\frac{d \phi}{d t} \cdot e^{-\int \frac{d t}{T}}-\frac{\phi(t)}{T} \cdot e^{-\int \frac{d t}{T}}
$$

After substitution (13) into equation (8)

$$
\frac{\mathrm{d} \phi}{\mathrm{dt}} \cdot \mathrm{e}^{-\int \frac{\mathrm{dt}}{\mathrm{T}}}-\frac{\phi(\mathrm{t})}{\mathrm{T}} \cdot \mathrm{e}^{-\int \frac{\mathrm{dt}}{\mathrm{T}}}+\frac{\phi(\mathrm{t})}{\mathrm{T}} \cdot \mathrm{e}^{-\int \frac{\mathrm{dt}}{\mathrm{T}}}=\mathrm{E} \cdot \frac{\mathrm{d} \varepsilon}{\mathrm{dt}} .
$$

So,

$$
\frac{\mathrm{d} \phi}{\mathrm{dt}}=\mathrm{E} \cdot \frac{\mathrm{d} \varepsilon}{\mathrm{dt}} \cdot \mathrm{e}^{\int \frac{\mathrm{dt}}{\mathrm{T}}}
$$


Integrating, let's define

$$
\phi(t)=\int E \cdot \frac{d \varepsilon}{d t} \cdot e^{j \frac{d t}{T}} d t+C_{1}
$$

After substitution (14) in (12) let's obtain

$$
\sigma_{X}(t)=\mathrm{e}^{-\int_{\mathrm{t}_{0}}^{\mathrm{t}} \frac{\mathrm{d}}{\mathrm{T}}}\left[\mathrm{C}_{1}+\int_{\mathrm{t}_{0}}^{\mathrm{t}} \mathrm{E} \frac{\mathrm{d} \varepsilon}{\mathrm{dt}} \cdot \mathrm{e}_{\mathrm{t}_{0}}^{\left.\int_{\mathrm{t}}^{\mathrm{t}} \frac{\mathrm{dt}}{\mathrm{T}} \mathrm{dt}\right]}\right.
$$

where $t_{0}$ and $t$ - the integration limits: $t_{0}$ - the beginning of the pause, and $t$ - the end of the pause.

Assuming that

$$
\bar{\varepsilon}=\frac{T}{A} \cdot \varepsilon_{X X}\left(1-e^{-\frac{A t}{T}}\right) \text { and } \sigma_{x x}^{0}=0
$$

let's obtain

$$
\frac{\mathrm{d} \bar{\varepsilon}}{\mathrm{dt}}=\dot{\varepsilon}_{\mathrm{XX}} \cdot \mathrm{e}^{-\frac{\mathrm{At}}{\mathrm{T}}}
$$

If $\mathrm{t}_{0}=0$, then

$$
\sigma_{X}(t)=e^{-\frac{t}{T}}\left[C_{1}+\int_{0}^{t} E \dot{\varepsilon}_{x x} e^{-\frac{A t}{T}} \cdot e^{\frac{t}{T}} d t\right]
$$

After appropriate transformations and using the initial condition $\sigma_{\mathrm{xx}}^{0}=0$, let's obtain

$$
\mathrm{C}=-\mathrm{E} \cdot \dot{\varepsilon}_{\mathrm{xx}} \cdot \frac{\mathrm{T}}{1-\mathrm{A}} .
$$

So,

$$
\sigma_{X}(t)=e^{-\frac{t}{T}}\left[-E \cdot \dot{\varepsilon}_{X x} \cdot \frac{T}{1-A}+\frac{T}{1-A} E \cdot \dot{\varepsilon}_{X x} \cdot e^{\frac{t}{T}(1-A)}\right]
$$

or

$$
\sigma_{X}(t)=E \cdot \dot{\varepsilon}_{x x} \cdot \frac{T}{1-A} \cdot\left[e^{-\frac{t A}{T}}-e^{-\frac{t}{T}}\right]
$$

When $A=1$, one should reveal the uncertainty of the form $\left\{\frac{0}{0}\right\}$ and come to a particular case
solution. Let's consider separately the case when $A \rightarrow 1$

$$
\begin{aligned}
& \sigma_{X X}=\lim _{A \rightarrow 1}\left[E \cdot \dot{\varepsilon}_{X X} \cdot \frac{T}{1-A}\left(e^{-\frac{t A}{T}}-e^{-\frac{t}{T}}\right)\right]=E \cdot \dot{\varepsilon}_{X X} \cdot T \cdot \lim _{A \rightarrow 1} \frac{e^{-\frac{t A}{T}}-e^{-\frac{t}{T}}}{1-A}=\left\{\frac{0}{0}\right\}= \\
& =E \cdot \dot{\varepsilon}_{X X} \cdot T \cdot \lim _{A \rightarrow 1} \frac{e^{-\frac{t}{T}}\left(e^{-\frac{t}{T}(A-1)}-1\right)}{1-A}=\left[e^{-\frac{t}{T}(A-1)}-1 \infty-\frac{t}{T}(A-1) a t A \rightarrow 1\right]= \\
& =E \cdot \dot{\varepsilon}_{X X} \cdot T \cdot \lim _{A \rightarrow 1} \frac{e^{-\frac{t}{T}}\left(-\frac{t}{T}(A-1)\right)}{1-A}=E \cdot \dot{\varepsilon}_{X X} \cdot T \cdot e^{-\frac{t}{T}} \cdot \frac{t}{T}=E \cdot \dot{\varepsilon}_{X X} \cdot t \cdot e^{-\frac{t}{T}}
\end{aligned}
$$


Therefore, when $A=1$, let's obtain

$$
\sigma_{\mathrm{XX}}=\mathrm{E} \cdot \dot{\varepsilon}_{\mathrm{XX}} \cdot \mathrm{t} \cdot \mathrm{e}^{-\frac{\mathrm{t}}{\mathrm{T}}}
$$

Taking into account the above, with $\mathrm{A}=1$, it is possible to simplify the functions describing the degree and rate of deformation (10) to the form:

$$
\bar{\varepsilon}=\mathrm{T} \cdot \dot{\varepsilon}_{\mathrm{xx}} \cdot\left(1-\mathrm{e}^{-\frac{\mathrm{t}}{\mathrm{T}}}\right), \frac{\mathrm{d} \bar{\varepsilon}}{\mathrm{dt}}=\dot{\varepsilon}_{\mathrm{xx}} \cdot \mathrm{e}^{-\frac{\mathrm{t}}{\mathrm{T}}}
$$

A mathematical procedure is carried out to solve the limit as $\mathrm{A} \rightarrow 1$ does not change the appearance of the functions for describing degrees and deformation rates; they are similar to those shown in Fig. 1. Analysis of the established model (15) allows to determine the results important for materials science:

- the maximum stress affects the Young's modulus at certain temperatures of deformation and rate of deformation;

- the peak of the function (15) corresponds to the time equal to $T=v / E$, that is, this is the moment when the pause (metal unloading) comes, does not contradict the mechanics of the deformation process. This time $\mathrm{T}$ can be calculated with a certain degree and rate of deformation, it is the initial data for solving the problem.

In addition, this model allows to determine the viscosity $v$ of a material from relation (7) through the product $\mathrm{T} \cdot \mathrm{E}$ or by fitting. According to the known deformation time, rate and degree of deformation, let's change the Young's modulus to match the values of the function (15) with the experiment. Thus, taking into account the viscous properties of the body is reduced to establishing the exact value of the Young's modulus, depending on the temperature level.

The solution to this problem is not difficult with a known material tensile diagram or in the presence of a hardening curve for different temperatures. Also, to determine the Young's modulus, it is possible to use the reference literature. Young's modulus with increasing temperature decreases exponentially.

The obtained model does not exclude the determination of the Young's modulus by the method of selection to the coincidence of the obtained dependence with the hardening-softening curve. Reducing the level of stress in the material after deformation (during a pause), according to the obtained model, occurs exponentially, does not contradict the actual behavior of the material after the load is removed. It does not require the specification of additional factors.

\section{Results of experimental studies of steel rheology during hot deformation}

To test the developed model of steel rheology during hot deformation, it is necessary to conduct experimental studies and compare them with the analytical model. In this case, it is necessary to establish the mechanical properties of the material that is deformed. The main factors affecting the mechanical properties of the material under study: temperature, degree and rate of deformation. Investigated steel: $40 \mathrm{X}, 9 \mathrm{X} \Phi, \mathrm{XB}, 10 \mathrm{X} 16 \mathrm{H} 8$. The temperature of steel samples varied in the range from 800 to $1200{ }^{\circ} \mathrm{C}$ with steps of $100{ }^{\circ} \mathrm{C}$. The deformation degree varies from 0 to 0.4 , the deformation rate in the range $(2 \ldots 6) \times 10^{-3} \mathrm{~s}^{-1}$, covers the deformation and high-speed mode of technological processes of forging and stamping. Experimental planning is carried out using type $3^{3} \mathrm{PFE}$ plan. The high-temperature mechanical properties of steels are studied jointly with Czestochowa University of Technology (Poland) on the Gleeble 3800 unit for physical modeling of thermomechanical compression and tension tests. After conducting experimental studies and processing the results obtained using the experiment planning theory, the coefficients of the regression equations are determined, which determine the dependence of the deformation resistance on the degree, deformation rate and temperature. After exclusion of non-significant coefficients:

$$
\begin{aligned}
& \sigma_{\mathrm{s}}(\varepsilon, \xi, \mathrm{T})=38+38 \cdot \mathrm{X}_{1}+18 \cdot \mathrm{X}_{2}-46 \cdot \mathrm{X}_{3}+21 \cdot \mathrm{X}_{2}{ }^{2}+29 \cdot \mathrm{X}_{3}{ }^{2}+ \\
& +39 \cdot \mathrm{X}_{1}{ }^{2} \cdot \mathrm{X}_{2}{ }^{2} \cdot \mathrm{X}_{3}{ }^{2}-26 \cdot \mathrm{X}_{1}{ }^{2} \cdot \mathrm{X}_{2}{ }^{2}-39 \cdot \mathrm{X}_{2}{ }^{2} \cdot \mathrm{X}_{3}{ }^{2}-19 \cdot \mathrm{X}_{1}{ }^{2} \cdot \mathrm{X}_{3}{ }^{2}
\end{aligned}
$$


where

$$
\mathrm{X}_{1}=\frac{\varepsilon-0,1}{0,1}, \mathrm{X}_{2}=\frac{\xi-6 \times 10^{-3}}{4 \times 10^{-3}}, \mathrm{X}_{3}=\frac{\mathrm{T}-1000}{200} \text {. }
$$

For comparison and verification of the theoretical and experimental results, equations (15) and (16) are used to construct the dependences of the deformation resistance during deformation with a pause at hot pressure treatment temperatures (Fig. 2). The experimental data are shown by the dashed line, and the theoretical ones by the solid line.

Graphically developed in the work dependence (15) is shown in Fig. $\mathbf{2}$ as a function, has areas of hardening and relaxation of stresses (softening) when removing the load. Fig. 2 shows experimental data of flow curves (curves 1 and 3) for various steels at a deformation rate $\dot{\varepsilon}=7 \times 10^{-3} \mathrm{~s}^{-1}$ and heating temperatures of $900{ }^{\circ} \mathrm{C}$ and $1000{ }^{\circ} \mathrm{C}$, function (15) is shown by curves 2 and 4 .
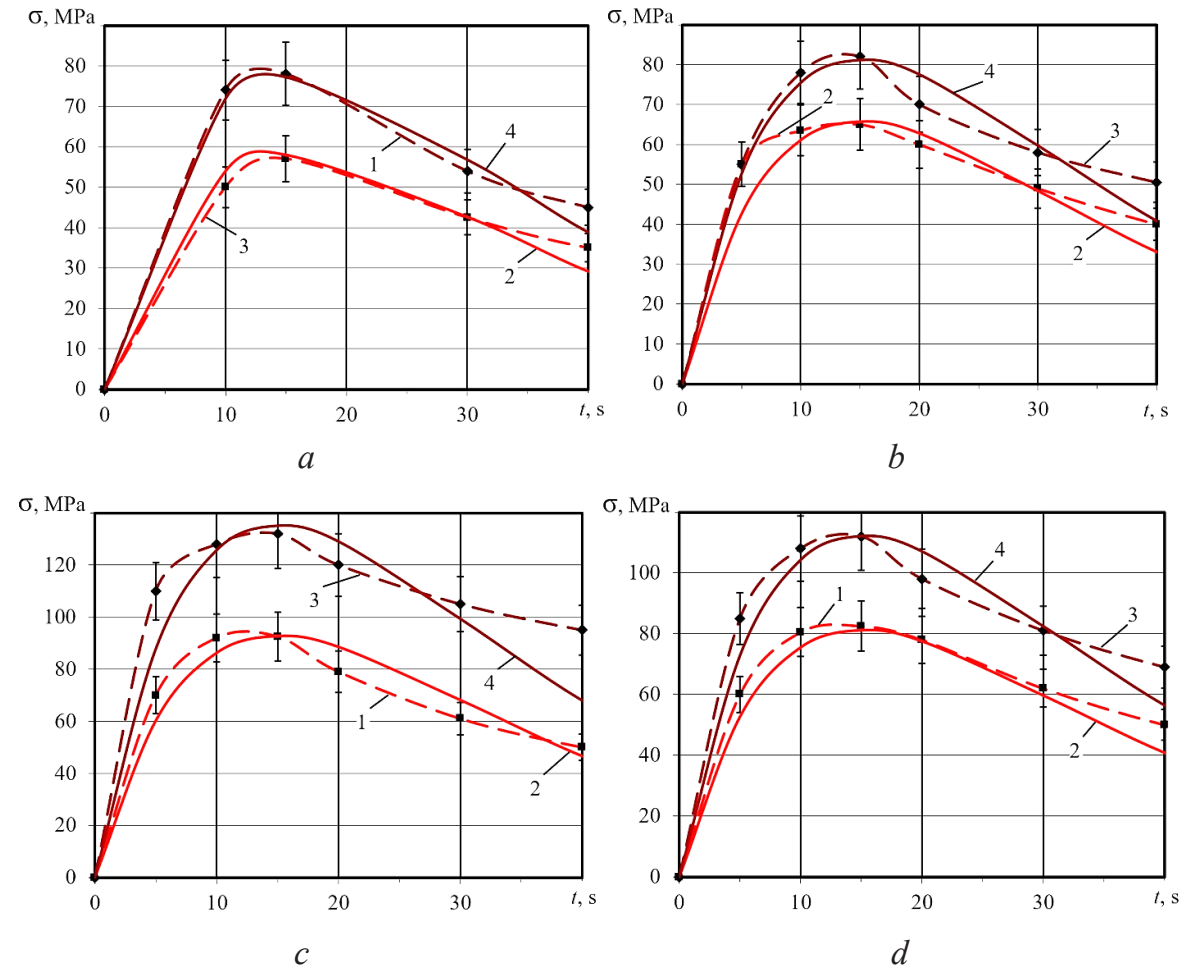

Fig. 2. Comparison of experimental data for hardening - softening with dependent (15) for steel: $a-40 \mathrm{X} ; b-9 \mathrm{X} \Phi ; c-\mathrm{XB} ; d-10 \mathrm{X} 16 \mathrm{H} 8 ; 1-\mathrm{T}=1000{ }^{\circ} \mathrm{C}$ (experiment);

$2-\mathrm{T}=1000{ }^{\circ} \mathrm{C}$ (calculations); $3-\mathrm{T}=900{ }^{\circ} \mathrm{C}$ (experiment); $4-\mathrm{T}=900{ }^{\circ} \mathrm{C}$ (calculations)

Comparison of the obtained theoretical data with the results of experiments shows their qualitative and quantitative correspondence. In the areas of hardening and relaxation, the difference is $7 . . .11 \%$.

\section{Discussion of the results obtained using the developed model of the visco-elastic behavior of steel at pressure treatment temperatures}

The analysis of the obtained results makes it possible to establish that a developed rheological model describes the physical processes occurring in hot-deformed steels - material hardening and stress relaxation. Based on the developed mathematical model, it is found that the maximum stress is determined by the Young's modulus for certain temperatures and material and deformation rate at the acoustic time of deformation. The peak of the function corresponds to the time $T=v / E$. The analytical dependence asymptotically approaches the state when the stress is zero, and the experimental data 
asymptotically approach a certain stress, which is the yield strength of the material. This difference is explained by the fact that during the experimental study, the specimen remained under load after deformation, due to the research method and the design of the cam plastometer. As a result, the stress can't be reduced to zero, since the load seems to act after the deformation process stops, so that it is possible to set a change in relaxation in the material after deformation is stopped. The difference between the experimental and calculated stress values at the relaxation site is the value of the yield strength of the material at a given temperature. Taking into account in the resulting model the effect of the load on the sample with a value equal to the yield strength of the material $\left(\sigma_{\mathrm{T}}\right)$, let's obtain the coincidence of dependencies with a deviation of $7 . .11 \%$. Thus, the reason for the discrepancy between the experimental data and the theoretical values of hardening and softening is established, which gives reason to consider the developed model to be reliable, since it describes the rheology of the metal during hot deformation by $89 . . .93 \%$.

In contrast to the existing methods for taking into account the mechanical properties of a material when FEM modeling, an analytical model is developed, which allows not to carry out iterative procedures. A feature of the developed model of the connection component of the deformation rate and stress during hot deformation is that it takes into account the mechanism of stress relaxation in the metal (alloy) after deformation. This opens up broad prospects for its use in FE modeling.

A limitation of this approach is the need to specify a Young's modulus for a certain material depending on temperature. This information is not enough in the literature today. Moreover, it is advisable to check the resulting model on other metals and alloys.

\section{Conclusions}

1. Based on Maxwell's viscoelastic rheological model, the relationship between the components of deformation rates and stresses is established. This makes it possible to obtain a direct numerical solution of nonlinear problems of hot plastic deformation in the course of modeling by the finite element method taking into account the real properties of the metal at high temperatures. As a result of using the developed model of the material rheology during deformation in the hot state in the calculation decreases by 4 times compared with the use of elastic and elastic-plastic models of materials used in commercial software products based on FEM. This is due to the exception of carrying out additional iterative procedures to establish the real resistance of the material for certain thermo-speed deformation conditions. The developed model takes into account not only the processes of material hardening during deformation, but also softening (stress relaxation) in the pause after deformation.

2. Resistance to hot deformation and stress relaxation after deformation of steels at different temperatures, degrees and deformation rates is experimentally established. Stress relaxation after hot deformation is explained by recrystallization processes. The obtained results are compared with theoretical data established on the basis of the developed model of material rheology during hot deformation. It is experimentally proved that the developed model is $89 . .93 \%$ describing the steel rheology during hot deformation.

\section{References}

[1] Markov, O., Zlygoriev, V., Gerasimenko, O., Hrudkina, N., Shevtsov, S. (2018). Improving the quality of forgings based on upsetting the workpieces with concave facets. Eastern-European Journal of Enterprise Technologies, 5 (1 (95)), 16-24. doi: https://doi.org/10.15587/1729-4061.2018.142674

[2] Buckingham, R. C., Argyrakis, C., Hardy, M. C., Birosca, S. (2016). The effect of strain distribution on microstructural developments during forging in a newly developed nickel base superalloy. Materials Science and Engineering: A, 654, 317-328. doi: https://doi.org/10.1016/j.msea.2015.12.042

[3] Ma, F., Lu, W., Qin, J., Zhang, D., Ji, B. (2007). The effect of forging temperature on microstructure and mechanical properties of in situ TiC/Ti composites. Materials \& Design, 28 (4), 1339-1342. doi: https://doi.org/10.1016/j.matdes.2006.02.004

[4] Ma, Q., Lin, Z., Yu, Z. (2009). Prediction of deformation behavior and microstructure evolution in heavy forging by FEM. The International Journal of Advanced Manufacturing Technology, 40 (3-4), 253-260. doi: https://doi.org/10.1007/s00170-007-1337-9 
[5] Pantalé, O., Gueye, B. (2013). Influence of the Constitutive Flow Law in FEM Simulation of the Radial Forging Process. Journal of Engineering, 2013, 1-8. doi: https://doi.org/10.1155/2013/231847

[6] Wu, Y., Dong, X., Yu, Q. (2015). Upper bound analysis of axial metal flow inhomogeneity in radial forging process. International Journal of Mechanical Sciences, 93, 102-110. doi: https://doi.org/10.1016/ j.ijmecsci.2015.01.012

[7] Kukhar, V., Burko, V., Prysiazhnyi, A., Balalayeva, E., Nyhnibeda, M. (2016). Development of alternative technology of dual forming of profiled workpiece obtained by buckling. Eastern-European Journal of Enterprise Technologies, 3 (7 (81)), 53-61. doi: https://doi.org/10.15587/1729-4061.2016.72063

[8] Dobrzański, L. A., Grajcar, A., Borek, W. (2008). Influence of hot-working conditions on a structure of high-manganese austenitic steels. Journal of Achievements in Materials and Manufacturing Engineering, 29 (2), 139-142.

[9] Weides, G., Blaes, N., Bokelmann, D. (2008). Optimisation of the forging process of profiled discs for low pressure turbine rotors by FEM simulation. 17 International Forgeмasters Meeting, Santander.

[10] Erman, E., Medei, N. M., Roesch, A. R., Shah, D. C. (1989). Physical modeling of the upsetting process in open-die press forging. Journal of Mechanical Working Technology, 19 (2), 195-210. doi: https:// doi.org/10.1016/0378-3804(89)90004-1

[11] Markov, O. E., Perig, A. V., Markova, M. A., Zlygoriev, V. N. (2015). Development of a new process for forging plates using intensive plastic deformation. The International Journal of Advanced Manufacturing Technology, 83 (9-12), 2159-2174. doi: https://doi.org/10.1007/s00170-015-8217-5

[12] Kitamura, K., Terano, M. (2014). Determination of local properties of plastic anisotropy in thick plate by small-cube compression test for precise simulation of plate forging. CIRP Annals, 63 (1), 293-296. doi: https://doi.org/10.1016/j.cirp.2014.03.038

[13] Markov, O. E. (2012). Forging of large pieces by tapered faces. Steel in Translation, 42 (12), 808-810. doi: https://doi.org/10.3103/s0967091212120054

[14] Mitani, Y., Mendoza, V., Osakada, K. (1991). Analysis of rotor shaft forging by rigid-plastic finite element method. Journal of Materials Processing Technology, 27 (1-3), 137-149. doi: https://doi.org/ 10.1016/0924-0136(91)90049-k

[15] Markov, O. E., Perig, A. V., Zlygoriev, V. N., Markova, M. A., Grin, A. G. (2016). A new process for forging shafts with convex dies. Research into the stressed state. The International Journal of Advanced Manufacturing Technology, 90 (1-4), 801-818. doi: https://doi.org/10.1007/s00170-016-9378-6

[16] Dragobetskii, V., Zagirnyak, M., Naumova, O., Shlyk, S., Shapoval, A. (2018). Method of Determination of Technological Durabilityof Plastically Deformed Sheet Parts of Vehicles. International Journal of Engineering \& Technology, 7 (4.3), 92-99. doi: https://doi.org/10.14419/ijet.v7i4.3.19558 